\title{
Selenium and the growth of Haemophilus ducreyi
}

\author{
D A VANDEN BERGHE
}

From the Laboratory of Microbiology, University of Antwerp, Antwerp, Belgium

SUMMARY One of the growth media in current use for Haemophilus ducreyi comprises Mueller Hinton agar, chocolatised horse blood, serum and IsoVitalex (BBL). For a better understanding of growth factors, attempts were made to simplify this complex medium. The horse blood was replaced by haemin $(200 \mu \mathrm{g} / \mathrm{ml})$, the serum by albumin $(0.2 \%)$, and IsoVitalex was substituted only by L-glutamine $0.01 \%$. Most of the strains grew, but when selenium ions were added in a concentration of $3.25 \times 10^{-3} \mu \mathrm{g} / \mathrm{ml}$, growth was stimulated and became more luxuriant than growth on conventional media.

In spite of the development of new media ${ }^{1-3}$ the isolation rate for Haemophilus ducreyi is still low. As it is not known what growth factors other than haemin are required, the composition of growth and isolation media is usually very rich and complex. Normally, only vancomycin is added to isolation plates to inhibit Gram positive organisms.

In a previous study ${ }^{4}$ a medium consisting of Mueller Hinton agar, haemin $200 \mu \mathrm{g} / \mathrm{ml}$, glucose $0.1 \%$, L-glutamine $0.01 \%$, cysteine hydrochloric acid $0.05 \%$ and albumin $0.2 \%$ was used for antimicrobial susceptibility testing. A low and narrow minimum inhibitory concentration range for sodium selenite (1-4 $\mu \mathrm{g} / \mathrm{ml})$ and copper II chloride $(2-8 \mu \mathrm{g} / \mathrm{ml})$ was found. In this study we tried to simplify further this medium and to examine the role of selenium and copper ions.

\section{Material and methods}

Isolates from South Africa (RC Ballard), Kenya (H Nsanze), Thailand (P Echeverria) and the Pasteur Institute Paris $(542,7866$, and 76118) were included.

Mueller Hinton agar (BBL Microbiology Systems) supplemented with haemin $200 \mu \mathrm{g} / \mathrm{ml}$ (BDH) was used as a base in each test. This base was sterilised by heat as indicated by the manufacturer $\left(121^{\circ} \mathrm{C}, 15\right.$ minutes). Stock solutions of the test products were sterilised by filtration and added to the base to give the desired final concentrations. These products were: bovine albumin fraction V (Sigma), L-glutamine (Merck), cysteine hydrochloride (BDH), glucose (Merck), glutamate (Calbiochem), glutathione
(Boehringer, reduccd), sodium selenite $\left(\mathrm{Na}_{2} \mathrm{Se}\right.$ $\mathrm{O}_{3} .5 \mathrm{H}_{2} \mathrm{O}$, Riedel-de Haen), copper chloride $\left(\mathrm{CuCl}_{2} .2 \mathrm{H}_{2} \mathrm{O}, \mathrm{Merck}\right)$.

Two different media were used as controls. One consisted of Mueller Hinton agar, chocolatised horse blood 5\% (Gibco), calf serum 5\% (Gibco), and IsoVitalex $1 \%$ (BBL). The other medium had the same composition, except for the horse blood which was substituted by haemin $200 \mu \mathrm{g} / \mathrm{ml}$.

Plates were streaked with a loopful of organisms and incubated for 48 hours in a microaerophilic and humid atmosphere at $33^{\circ} \mathrm{C}$. Strains that showed growth were subcultured on the same medium and incubated in similar conditions.

\section{Results}

Strains were given a + score when growth after subculture was comparable with growth on the control plates. If growth was more luxuriant than the control, ++ was given. A hazy growth was indicated as \pm .

As glucose, L-glutamine, and cysteine hydrochloric acid are generally considered to be the three components of IsoVitalex that are really necessary for $H$ ducreyi, these products were first investigated on a limited number of strains (table 1). All strains grew well in the presence of L-glutamine, alone or in combination with the other compounds. Cysteine hydrochloric acid and glucose were not able to support or enhance growth. Growth was diminished in the absence of albumin.

The question arose whether $H$ ducreyi specifically requires L-glutamine for growth, or whether glutamate as a precursor, or glutathione as a generated product from glutamine would have the same effect. 
Table 1 Influence of glucose, L-glutamine, and cysteine-hydrochloric acid with and without albumin on the growth of $\mathrm{H}$ ducreyi

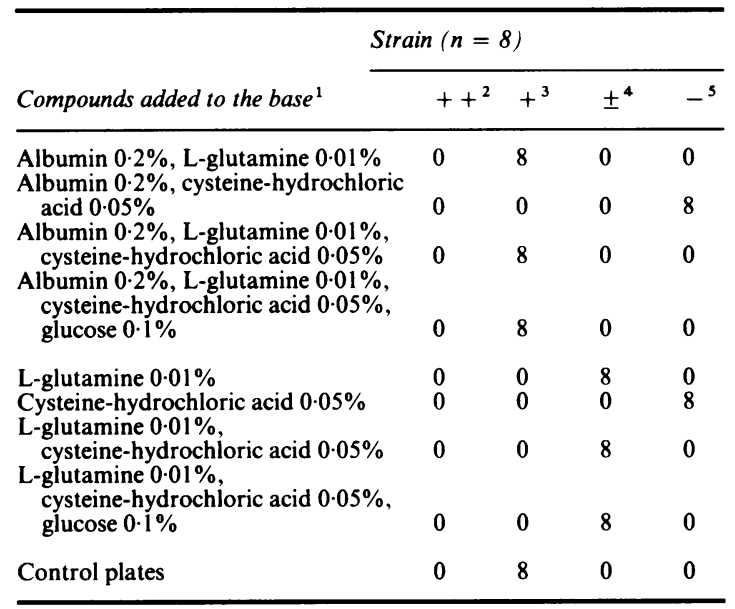

${ }^{1}$ base: Mueller Hinton agar + haemin $(200 \mu \mathrm{g} / \mathrm{ml})$.

$2++$ : Luxuriant growth.

$3+$ : Good growth (comparable with control plates).

4 : Hazy growth

Table 2 gives the results. Only L-glutamine was able to make the strains grow. Good growth $(+)$ was seen at a concentration of $0.01 \%$. Two strains failed to grow at this concentration, yet they showed a hazy growth at higher concentrations.

Table 3 shows the influence of sodium selenite. Sodium selenite alone, in concentrations 10,100 , and 1000 times less than the minimum inhibitory concentration value, has no effect on the strains, but combined with L-glutamine, a very good growth that was at least comparable $(+)$ and in most cases more luxuriant $(++)$ than that on the control plates was seen.

Table 4 gives the results with copper II chloride.
Copper II chloride alone does not support growth, but combined with L-glutamine is comparable with the results obtained with L-glutamine and albumin as the only additive.

\section{Discussion}

$H$ ducreyi has always been known to be a fastidious organism. Growth conditions are generally accepted as $33-35^{\circ} \mathrm{C}$ and a humid atmosphere with reduced oxygen and enhanced carbon dioxide tension. Growth factors, however, are still poorly understood. As a consequence isolation media are very rich and hardly selective so that isolation ratios have always been low.

In an attempt to investigate $H$ ducreyi growth factors we tried to simplify one of the conventional media, composed of Mueller Hinton agar, chocolatised horse blood $5 \%$, serum $5 \%$, and IsoVitalex 1 or $2 \%$ (BBL). The horse blood was replaced by haemin $200 \mu \mathrm{g} / \mathrm{ml}$ and the serum by albumin $0 \cdot 2 \%$. Growth in the presence of albumin was comparable with control growth, but without albumin, growth was much less. $H$ ducreyi prefers a high protein concentration, rather than some specific serum factor. This is not surprising as carbohydrate metabolism cannot be detected by conventional sugar fermentation tests, while aminopeptidases and proteases are common. ${ }^{5}$

The only component from IsoVitalex really required by $H$ ducreyi is L-glutamine (table 1 ) in a concentration of $0.01 \%$. This is exactly the concentration of glutamine in a medium supplemented with $1 \%$ IsoVitalex. It is likely that the strains we used were adapted to this concentration by isolation and subculturing on the classical medium. Some strains still failed to grow.

Table 2 Influence of L-glutamine, glutamate, and glutathione in various concentrations on the growth of $H$ ducreyi (strains $=12$ )

\begin{tabular}{|c|c|c|c|c|c|c|c|c|c|c|c|c|}
\hline \multirow{3}{*}{$C(\% w / v o l)$} & \multicolumn{12}{|c|}{ Base $^{1}+$ albumin $0 \cdot 2 \%$} \\
\hline & \multicolumn{4}{|c|}{ L-glutamine } & \multicolumn{4}{|c|}{ Glutamate } & \multicolumn{4}{|c|}{ Glutathione } \\
\hline & $++^{2}$ & $++^{3}$ & $\pm^{4}$ & -5 & ++ & + & \pm & - & ++ & + & \pm & - \\
\hline $0 \cdot 1$ & 0 & 0 & 0 & 12 & 0 & 0 & 0 & 12 & 0 & 0 & 0 & 12 \\
\hline 0.05 & 0 & 0 & 12 & 0 & 0 & 0 & 0 & 12 & 0 & 0 & 0 & 12 \\
\hline 0.025 & 0 & 0 & 12 & 0 & 0 & 0 & 0 & 12 & 0 & 0 & 0 & 12 \\
\hline 0.01 & 0 & 10 & 0 & 2 & 0 & 0 & 0 & 12 & 0 & 0 & 0 & 12 \\
\hline 0.005 & 0 & 0 & 10 & 2 & 0 & 0 & 0 & 12 & 0 & 0 & 0 & 12 \\
\hline
\end{tabular}

Control plates for all 12 strains: + .

'base: Mueller Hinton agar + haemin $(200 \mu \mathrm{g} / \mathrm{ml})$.

$2++$ : Luxuriant growth.

${ }^{3}+$ : Good growth (comparable with control plates).

$4 \pm$ : Hazy growth.

$5 \pm$ : No growth. 
Table 3 Influence of sodium selenite alone and in combination with L-glutamine on the growth of $H$ ducreyi

\begin{tabular}{|c|c|c|c|c|c|c|c|c|}
\hline \multirow{3}{*}{$\begin{array}{l}\text { Sodium selenite concentration } \\
(\mu \mathrm{g} / \mathrm{ml})\end{array}$} & \multicolumn{8}{|c|}{ Base $^{1}+$ albumin $0 \cdot 2 \%$} \\
\hline & \multicolumn{4}{|c|}{ Without L-glutamine (strains $n=9$ ) } & \multicolumn{4}{|c|}{ With L-glutamine (strains $n=19$ ) } \\
\hline & $+t^{2}$ & $++^{3}$ & $\pm^{4}$ & -5 & ++ & + & \pm & - \\
\hline $0 \cdot 1$ & 0 & 0 & 0 & 9 & 0 & 7 & 5 & 7 \\
\hline 0.05 & 0 & 0 & 0 & 9 & 0 & 14 & 0 & 5 \\
\hline 0.01 & 0 & 0 & 0 & 9 & 19 & 0 & 0 & 0 \\
\hline 0.005 & 0 & 0 & 0 & 9 & 0 & 0 & 19 & 0 \\
\hline 0.001 & 0 & 0 & 0 & 9 & 0 & 0 & 19 & 0 \\
\hline Control plates & 0 & 9 & 0 & 0 & 0 & 19 & 0 & 0 \\
\hline
\end{tabular}

'base: Mueller Hinton agar + haemin $(200 \mu \mathrm{g} / \mathrm{ml})$

$2++$ : Luxuriant growth.

$3+$ : Good growth (comparable with control plates)

\pm : Hazy growth.

5 : No growth.

Table 4 Influence of copper II chloride alone and in combination with L-glutamine on the growth of $H$ ducreyi

\begin{tabular}{|c|c|c|c|c|c|c|c|c|}
\hline \multirow{3}{*}{$\begin{array}{l}\text { Copper II chloride concentration } \\
(\mu \mathrm{g} / \mathrm{ml})\end{array}$} & \multicolumn{8}{|c|}{ Base $^{1}+$ albumin $0.2 \%$} \\
\hline & \multicolumn{4}{|c|}{ Without L-glutamine (strains $n=19$ ) } & \multicolumn{4}{|c|}{ With L-glutamine (strains $n=19$ ) } \\
\hline & $++^{2}$ & $t^{3}$ & $\pm^{4}$ & -5 & ++ & + & \pm & - \\
\hline 0.1 & 0 & 0 & 0 & 19 & 0 & 12 & 7 & 0 \\
\hline 0.05 & 0 & 0 & 0 & 19 & 0 & 17 & 2 & 0 \\
\hline 0.01 & 0 & 0 & 0 & 19 & 0 & 9 & 10 & 0 \\
\hline 0.005 & 0 & 0 & 0 & 19 & 0 & 16 & 0 & 3 \\
\hline 0.001 & 0 & 0 & 0 & 19 & 0 & 15 & 1 & 3 \\
\hline Control plates & 0 & 19 & 0 & 0 & 0 & 19 & 0 & 0 \\
\hline
\end{tabular}

${ }^{1}$ base: Mueller Hinton agar + haemin $(200 \mu \mathrm{g} / \mathrm{ml})$.

$2++$ : Luxuriant growth.

$3+$ : Good growth (comparable with control plates).

4. Hazy growth.

Surprisingly neither glutamate nor glutathione are able to support growth (table 2).

In view of previous studies of minimum inhibitory concentration ${ }^{4}$ we examined the influence of selenium ions in concentrations below the minimum inhibitory concentration. Selenium ions alone were not able to support growth. In combination with glutamine, however, all strains showed luxuriant growth (table 3 ). The optimal sodium selenite concentration was found to be $0.01 \mu \mathrm{g} / \mathrm{ml}$, corresponding to $3.25 \times$ $10^{-3} \mu \mathrm{g} / \mathrm{ml}$ selenium ions.

Glutathione is the substrate of the enzyme glutathione peroxidase, which is a seleno enzyme. The combination of glutathione and selenium ions was not able to support growth. It seems, therefore, that glutamine and selenium act separately. The action of selenium is a very specific one, as copper ions do not have any influence, in spite of almost comparable minimum inhibitory concentration values (table 4 )
(1-4 $\mu \mathrm{g} / \mathrm{ml}$ for sodium selenite, $2-8 \mu \mathrm{g} / \mathrm{ml}$ for copper II chloride).

As the optimal selenium concentration is so critical some interesting consequences can be considered Selenium is a trace element spread across the world with a considerable variety of forms. The selenium concentrations in blood and body fluids reflect dietary intake, which in its turn reflects environmental selenium. ${ }^{6-8}$ Thus it would be worthwhile to examine the role of selenium in the pathogenesis of chancroid.

On the other hand, most isolation media are supplemented with whole blood and serum. As selenium concentration is crucial, batches of blood and serum, differing in selenium concentration, should give different isolation ratios. In regions where soil and water selenium concentration are high, one can also expect an influence from the water used to prepare media, if this is not properly deionised. 


\section{References}

1 Hafiz S, McEntegart MG, Kinghorn GR. Sheffield medium for cultivation of Haemophilus ducreyi. British Journal of Venereal Disease 1984;60:196-8.

2 Oberhofer TR, Back AE. Isolation and cultivation of Haemophilus ducreyi. J Clin Microbiol 1982;15:625-9.

3 Hammond GW, Slutchuk M, Scatliff J, Sherman E, Wilt JC, Ronald AR. Epidemiologic, clinical, laboratory and therapeutic features of an urban outbreak of chancroid in North America. Rev Infect Dis 1980;2:867-79.

4 Slootmans L, Vanden Berghe DA, Van Dijck E, Piot P. Susceptibility of 40 Haemophilus ducreyi strains to 34 antimicrobial products. Antimicrob Agents Chemother 1983; 24:564-7.

5 Casin IM, Sanson-Le Pors MJ, Gorce MF, Ortenberg M, Pérol Y. The enzymatic profile of Haemophilus ducreyi. Ann Inst Pasteur Microbiol 1982;133B:379-88.
6 McKenzie RL, Rea HM, Thomson CD, Robinson MF. Selenium concentration and glutathione peroxidase activity in blood of New Zealand infants and children. Am J Clin Nutr 1978;31:1413-8.

7 Westermarck T, Raunu P, Kirjarinta M, Lappalainen L. Selenium content of whole blood and serum in adults and children of different ages from different parts of Finland. Acta Pharmacol Et Toxicol 1977;40:465-75.

8 Thomson CD, Robinson MF, Campbell DR, Rea HM. Effect of prolonged supplementation with daily supplements of selenomethionine and sodium selenite on glutathione peroxidase activity in blood of New Zealand residents. Am J Clin Nutr 1982;36:24-31.

Requests for reprints to: Professor DA Vanden Berghe, Laboratory of Microbiology, University of Antwerp, UIA, 2610 Antwerpen, Belgium. 